\title{
O ILÊ OBÁ OGUNTÉ: PATRIMÔNIO E IDENTIDADE AFRO-BRASILEIRA
}

\section{ILÊ OBÁ OGUNTÉ: \\ AFRO-BRAZILIAN HERITAGE AND IDENTITY}

\section{Zuleica Dantas Pereira Campos}

zuleica.campos@unicap.br

Professora Titular e Coordenadora do Programa de Pós-graduação em Ciências da Religião da UNICAP, Doutora em História do Brasil

ORCID: http://orcid.org/0000-0002-4149-1833.

\section{RESUMO}

O objetivo deste trabalho é refletir sobre o processo de patrimonialização ocorrido nas religiões afro-brasileiras e a importância atribuída à musealização da sua cultura, tanto material quanto imaterial. Para tanto, tomamos como estudo o Ilê Obá Ogunté, localizado no Recife, Pernambuco. O terreiro conta com o reconhecimento não só dos adeptos, mas de estudiosos especializados uma vez que se constitui no espaço de culto mais antigo em funcionamento na cidade. A partir de nossas investigações, buscamos explicitar que os processos de patrimonialização lidam com a religião e com a identidade afro-brasileira no sentido de inserir seus praticantes na história das lutas por legitimidade.

Palavras-chave: religiões afro-brasileiras; patrimonialização; resistência; espaço público.

\section{ABSTRACT}

The aim of this paper is to reflect on the process of patrimonialization that occurred in Afro-Brazilian religions and the importance given to the musealization of their culture, both material and non-material. Therefore, we took as study Ilê Obá Ogunté, located in Recife, Pernambuco. The terreiro counts with the recognition not only of the adepts but of specialized scholars since it constitutes the oldest place of worship in operation in the City. From our investigations, we seek to clarify that the patrimonialization processes deal with religion and Afro-Brazilian identity in order to insert their practitioners in the history of struggles for legitimacy.

Keywords: Afro-brazilian religions; patrimonialization; resistance; public space.

\section{INTRODUÇÃO}

As expressões da religiosidade afro-brasileira são caracterizadas historicamente sob o rótulo de cultura na leitura de nossa sociedade. Inclusive, estão inseridas no roteiro turístico de várias cidades e tendo manifestações associadas a elas, tais como maracatus, afoxés, rodas de coco e outras, apresentadas nos espaços públicos como atrações da cultura popular. 
A partir dos movimentos modernista e regionalista, que trouxeram em seu bojo a valorização dos aspectos nacional e popular, é que os elementos da cultura afro-brasileira foram valorizados e incluídos na categoria de cultura popular ou folclore e, a partir daí, em cultura brasileira. O popular era definido por uma série de características internas e por um conjunto de conteúdos tradicionais, anteriores à industrialização e à massificação da cultura. Como parte da cultura popular, a cultura afro-brasileira fica associada ao não moderno, congelada no tempo, ou então, é atualizada, modernizada como parte da cultura brasileira.

As religiões desempenharam um papel particular nesse processo. Interpretadas, por um lado, como reprodução da África no Brasil, e, por outro, como espaços históricos de resistência da população negra, tiveram na aceitação do rótulo de folclore ou manifestação cultural uma estratégia de negociação para uma entrada possível em espaços socialmente valorizados. Em consequência, ficamos acostumados a ver apresentações das religiões afrodescendentes realizadas em festas, inaugurações e outros eventos públicos

A preservação do patrimônio afro-religioso no Brasil é temática que vem sendo abordada desde finais do século passado, demarcando as primeiras políticas públicas patrimoniais voltadas para o tombamento das casas de culto afro-brasileiras (VELHO, 2006; SERRA, 2005). Devemos ressaltar que os movimentos sociais negros estabeleceram uma política efetiva para a viabilização do processo, uma vez que tomaram essas religiões como parte de suas identidades e ancestralidades.

Trata-se da preservação de um complexo cultural (valores, saberes, símbolos, traços culturais e visão de mundo) africano, na cultura brasileira. As religiões afro-brasileiras são, por assim dizer, apresentadas como depositárias e continuadoras da cosmovisão africana no Brasil. Dessa forma, foi a partir da imagem da África construída no Brasil, no interior dos grupos religiosos afro-brasileiros, que se buscou resguardar um conjunto cultural até então invisibilizado pelas políticas patrimoniais.

É a partir desse contexto que o objetivo deste trabalho é refletir sobre o processo de patrimonialização ocorrido nas religiões afro-brasileiras e a importância atribuída à musealização da sua cultura, tanto material quanto não material. Para tanto, daremos como exemplo um terreiro recentemente (2018) reconhecido pelo IPHAN como patrimônio cultural do Brasil, o Ilê Obá Ogunté, localizado no Recife, Pernambuco.

\section{PATRIMONIALIZAÇÃO, MOVIMENTOS SOCIAIS NEGROS E IDENTIDADE}

O movimento de tombamento de terreiros implica a oficialização, por parte do governo federal, do "reconhecimento do significado histórico desses centros de culto enquanto depositários da memória de um 
importante segmento da população brasileira, e se afirmou o valor do acervo de bens culturais neles encerrados" (SERRA, 2005, p. 3).

Essa preservação dos valores de tradição africana é entendida como um processo ameaçado. Daí a preocupação dos movimentos sociais negros para que o Estado assuma a proteção do seu patrimônio. Assim, ações voltadas para a preservação do patrimônio - cultural, material e socioambiental - das religiões, apresentados, simultaneamente, como marca da diacrítica da identidade afro-brasileira e como contribuição dos afrodescendentes à cultura nacional.

\section{Para Renato Ortiz,}

O lugar que o universo religioso ocupava nas sociedades tradicionais foi definitivamente remodelado pela modernidade. Entretanto, não se pode deixar de entender que a ação das religiões no mundo globalizado toma uma outra configuração (ORTIZ, 2002, p. 89).

Essas novas configurações não se traduziam apenas nas transformações em busca de espaços no mercado religioso. Elas também se traduziram em lutas políticas junto aos órgãos públicos e às políticas pela igualdade "racial", levadas a efeito através dos processos de patrimonialização e musealização dos terreiros.

Entendemos que patrimonializar é atuar, conscientemente,

No campo patrimonial: um campo específico de análise, voltado para o estudo e a tentativa de compreensão das estratégias de instituição, reconhecimento e utilização do patrimônio, no âmbito das diferentes sociedades, em todos os momentos de sua trajetória: seja no reconhecimento das matrizes constitutivas, ou na análise das tensões entre tradição e modernidade, ou entre processos inclusivos e processos de exclusão (SCHEINER, 2009, p. 53).

Já musealizar é atuar, conscientemente, com o fenômeno da musealidade, valor simbólico atribuído a determinadas referências e/ou representações na natureza ou da cultura. (SCHEINER, 2009, p. 54). As relações entre patrimonialização e musealização são constantes, embora não se confundam. Podemos citar especialmente o "patrimônio musealizável, ou musealizado em relação direta ou indireta com a sua apreensão/institucionalização pelos museus, e, o patrimônio como ideia, evento ou manifestação - fundamento constitutivo do próprio fenômeno Museu" (SCHEINER, 2009, p. 54). Assim, diversas casas de culto afro-brasileiro chegaram ao século XXI reinterpretadas, patrimonializadas e musealizadas.

Diante desse contexto, podemos perceber que é através do mote da preservação/transmissão dos valores das religiões afro-brasileiras, que aqueles que lutam pelo reconhecimento, tanto da especificidade da cultura negra como da sua contribuição para a constituição da cultura nacional, apegam-se para fazer valer os seus direitos. Desta forma, os conteúdos religiosos se misturam com os conteúdos patrimoniais e museais, através do vetor identitário e das políticas públicas de repara- 
ção e afirmação afrodescendentes, conformando um novo ambiente de disputa política.

Se observarmos o texto das Conferências de Promoção da Igualdade Racial, veremos que o reconhecimento das religiões afrodescendentes como patrimônio imaterial, cultural e religioso brasileiro constitui uma das bandeiras centrais dentre as apresentadas pelos participantes, como podemos perceber nas propostas que seguem:

Capitulo: Cultura:

4. Assegurar o cumprimento dos instrumentos jurídicos já existentes de combate à descaracterização dos valores culturais afro-brasileiros, visando o fortalecimento e reconhecimento das religiões de matriz africana e afro-brasileira como patrimônio imaterial cultural e religioso brasileiro, com a criação de políticas de fomento que assegurem, inclusive, a preservação dos ambientes naturais indispensáveis à manutenção dos rituais sagrados.

\section{$[\ldots]$}

6. Reconhecer enquanto patrimônio material e imaterial nacional os terreiros, os babalorixás, yalorixás, sacerdotes e sacerdotisas como perpetuadores das religiões de matriz africana e afro-brasileira, garantir o reconhecimento legal dos terreiros como meio de promoção da cultura, educação e saúde, bem como fortalecer ações já desenvolvidas no âmbito nacional e seu reconhecimento como de utilidade pública (BRASIL, 2005, p. 15. Grifos nossos).

Esta é uma política de representação identitária que tomou a religião afro-brasileira como ícone máximo da identidade negra, à qual se somaram, ainda, os demais elementos, ditos culturais, como os maracatus, os afoxés, a musicalidade, a estética, entre outros que foram articulados a vieses religiosos, garantidores de uma legitimidade africana.

O primeiro caso de tombamento no âmbito federal foi o do terreiro da Casa Branca, localizado em Salvador, na Bahia, em 1982. De acordo com Corrêa (2007), o Movimento Negro Unificado (MNU) buscava, através do tombamento, obter "um reconhecimento simbólico dos bens e valores referentes à sua cultura” (2007, p. 86). Nessa perspectiva, seus militantes recusavam "a ideia de que o terreiro da Casa Branca fosse inscrito no volume 'etnográfico' do Livro do Tombo. Consideraram essa categoria pejorativa e impregnada de etnocentrismo. Pois, por que um terreiro de candomblé deveria ser considerado 'etnográfico' e uma igreja católica deveria ser patrimônio histórico?” (CORRÊA, 2007, p. 87).

Chamando a atenção para o aspecto de disputa política envolvido na definição e na identificação dessas categorias, o autor explicita ainda que, do ponto de vista do movimento social negro: “[...] a categoria 'etnográfico' colocava o bem cultural no plano dos objetos e acervos 'primitivos' e 'exóticos' - algo considerado inaceitável e que seria avaliado com um ato colonialista e etnocêntrico" (CORRÊA, 2007, p. 87). 
O que a disputa exposta acima permite compreender é o fato de que, no cerne das demandas relativas à valorização do patrimônio cultural afro-brasileiro, encontra-se uma busca por legitimação e reconhecimento da contribuição civilizatória aportada pelos povos africanos trazidos ao Brasil - seus valores e visão de mundo -, em equidade em relação à contribuição europeia.

Conforme assinalamos, essas disputas têm como objetivo colocar na pauta dos órgãos responsáveis pela política de preservação a valorização das referências culturais relacionadas à identidade negra, em contraposição àquelas apresentadas como fundadoras de um ideal unificado de nação.

Assim, o reconhecimento das religiões afrodescendentes como parte do patrimônio cultural brasileiro se inscreve no contexto de uma luta política engendrada pela presença, neste debate, de novos atores, em particular o movimento social negro.

Vale ressaltar que, historicamente, os espaços sagrados valorizados no Brasil são as igrejas católicas, principalmente aquelas em estilo barroco. Bastide, na década de 1940, quando escreve "Imagens do Nordeste místico em branco e preto", exalta o barroco e o rococó das igrejas da Bahia e de Pernambuco. Para o autor:

O barroco não é apenas uma forma de arte. É também um estilo de vida. Desprende-se das paredes das igrejas, das fachadas dos palácios, desce as escadarias majestosas para se estender pelos jardins, com suas grandes avenidas que terminam em horizontes azulados, para tomar posse do corpo humano (BASTIDE, 1945, p. 32).

Também se destacam as igrejas maneiristas, ecléticas e modernistas - a exemplo da Catedral de Brasília, de Oscar Niemeyer.

A estética europeia goza de uma representação efetiva no campo ainda bastante elitista do patrimônio. Assim, é necessário que atendam determinados padrões técnicos, estéticos e culturais próprios da qualidade erudita, no sentido do pertencimento à civilização ocidental. Como informa Chuva (2003), as políticas federais de patrimonialização remontam ao ano de 1937, com a criação do Serviço do Patrimônio Histórico e Artístico Nacional - o SPHAN. E em torno dele, um conjunto de intelectuais modernistas, cujos debates acerca de uma "arquitetura à brasileira” foram travados na "Revista do SPHAN". Dessa forma, as políticas patrimoniais refletiam a ideologia de uma elite cultural e política, que estava à frente do processo de construção de uma identidade nacional.

Só a partir da década de 1980, com as lutas históricas dos movimentos sociais negros e o processo de redemocratização da sociedade brasileira, que tem como marco a constituição cidadã de 1988 e a concepção de imaterialidade, é que se expandiu a definição de arte, até então limitada à civilização europeia.

Em 1937, através de um Decreto-lei, o Brasil define patrimônio histórico e artístico nacional como, 
conjunto dos bens móveis e imóveis existentes no país e cuja conservação seja de interêsse público, quer por sua vinculação a fatos memoráveis da história do Brasil, quer por seu excepcional valor arqueológico ou etnográfico, bibliográfico ou artístico (BRASIL, 1937).

Só com a Constituição de 1988 é que se alarga o conceito de patrimônio, redefinindo-o como:

Constituem patrimônio cultural brasileiro os bens de natureza material e imaterial, tomados individualmente ou em conjunto, portadores de referência à identidade, à ação, à memória dos diferentes grupos formadores da sociedade brasileira, nos quais se incluem:

I - as formas de expressão;

II - os modos de criar, fazer e viver;

III - as criações científicas, artísticas e tecnológicas;

IV - as obras, objetos, documentos, edificações e demais espaços destinados às manifestações artístico-culturais;

V - os conjuntos urbanos e sítios de valor histórico, paisagístico, artístico, arqueológico, paleontológico, ecológico e científico (BRASIL, 1988).

A concepção de imaterialidade foi tão impactante para os padrões da época que Francisco Weffort, quando Ministro da Cultura² ${ }^{2}$ expôs em carta ao Presidente da República os motivos da criação e do registro de um patrimônio imaterial. Justificou sua utilidade da seguinte forma: “instituir obrigação pública e governamental, sobretudo de inventariar, documentar, acompanhar e apoiar a dinâmica das manifestações culturais, mecanismo fundamental para a preservação de sua memória" (WEFFORT, 2003, p. 26).

No diálogo com essas demandas, seguiu-se a elaboração de um arcabouço legal capaz de contemplar uma noção ampliada do conceito de patrimônio. Este processo culminou com a publicação, no ano de 2000, do Decreto-Lei 3.551, que visava a regulamentar o Registro de Bens Culturais de Natureza Imaterial por parte do IPHAN. Para tanto, o referido Decreto enumera as categorias nas quais os bens culturais poderão ser inscritos nos chamados Livros de Registro, de acordo com a sua natureza ${ }^{3}$ e cria o Programa Nacional de Patrimônio Imaterial.

No detalhamento dessas diretrizes o IPHAN publicou, em 23 de março de 2007, a Resolução nº 01/2006, que regulamenta os procedimentos de abertura e instrução técnica dos processos administrativos de Registro. De acordo com a Resolução, entende-se como bem cultural de natureza imaterial "as criações culturais de caráter dinâmico e processual, fundadas na tradição e manifestadas por indivíduos ou grupos de indivíduos como expressão de sua identidade cultural e social" (BRASIL, 2007). O texto prossegue afirmando que uma manifestação cultural se torna "tradição no seu sentido etimológico de "dizer através do tempo", significando práticas produtivas, rituais e simbólicas que são constantemente reiteradas, transformadas e atualizadas, mantendo, para o grupo, um vínculo do presente com o seu passado" (BRASIL, 2007). 
Ao avaliar os dez anos de experiência do Programa Nacional de Patrimônio Imaterial - PNPI, Jundurian Corá et al. (2011, p. 19) afirmam que a partir da implantação de uma política pública voltada para o patrimônio imaterial:

O Estado passa não só a preservar, mas valorizar a cultura popular contemplada pelas celebrações, formas de expressão, lugares e saberes - como forma legítima de representação da cultura brasileira, incluindo assim, o debate da diversidade cultural e permitindo a possibilidade da utilização da cultura para o fomento da geração de trabalho e renda e valorização identitária para os grupos detentores de suas práticas (Grifos nossos).

Ao mesmo tempo, é importante referir, tanto no campo do patrimônio cultural, quanto no campo da museologia, as políticas afirmativas dos governos pós-redemocratização do Brasil, quando os órgãos estatais mudaram sua forma de atuação, entendendo que:

o patrimônio cultural brasileiro não devia restringir-se a grandes monumentos, aos testemunhos da história oficial, na qual, sobretudo as elites se reconheciam, mas também deviam incluir as manifestações culturais representativas para outros grupos que compõem a sociedade brasileira - os índios, os negros, os imigrantes, as classes populares em geral (FONSECA, 2002, p. 191).

É no entendimento dessas categorias - cultura popular; cultura brasileira; diversidade cultural; tradição e identidade - que residem alguns dos pontos cruciais do processo de reconhecimento das religiões afrodescendentes como bens culturais imateriais.

\section{O CASO DO SÍTIO DO PAI ADÃO OU ILÊ OBÁ OGUNTÉ}

Considerado pela população religiosa afrodescendente a casa matriz do Xangô de Pernambuco, o Ilê Obá Ogunté é a primeira casa de culto oficialmente declarada na cidade do Recife, uma vez que não se encontram registros de nenhum outro grupo em atuação na época de sua fundação. É conhecido como "Sítio de Pai Adão", ou apenas "O Sítio". Fernandes (1937), ao se referir à localização dos principais terreiros do Recife na década de 1930, denomina-o de "Seita Africana Ôbaoumin", e mais adiante como "Sítio Chapéo do Sol". Em pesquisas realizadas entre os fins da década de 1980 e primeira metade da década de 1990, tomamos conhecimento de várias outras denominações tais como:

Antigamente chamava-se Sítio da Tia Inês, mas depois que ela morreu passou a ser o Sítio do Pai Adão. Agora, o nome certo é Iemanjá Ogunté, que era a Iemanjá da Tia Inês. Quando D. Joaninha veio para o Sítio, adotou o nome de Iemanjá Ogundê, que era a sua Iemanjá... (BONFIM, 1992). 


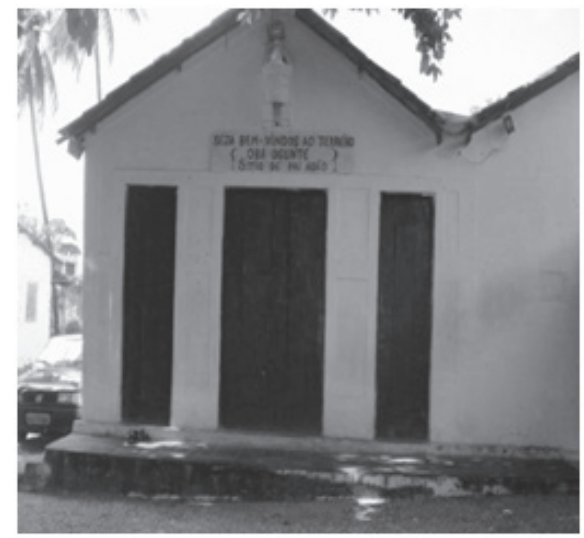

Figura 1 - Capela de Santa Inês Arquivo pessoal da pesquisadora, 2018

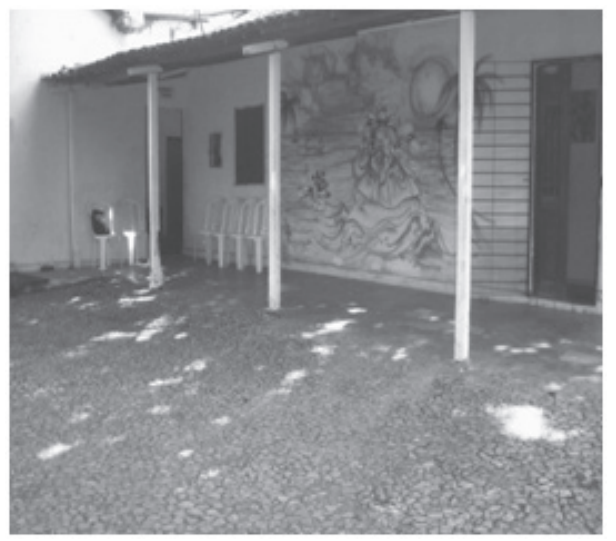

Figura 2 - Entrada da construção principal Arquivo pessoal da pesquisadora, 2018

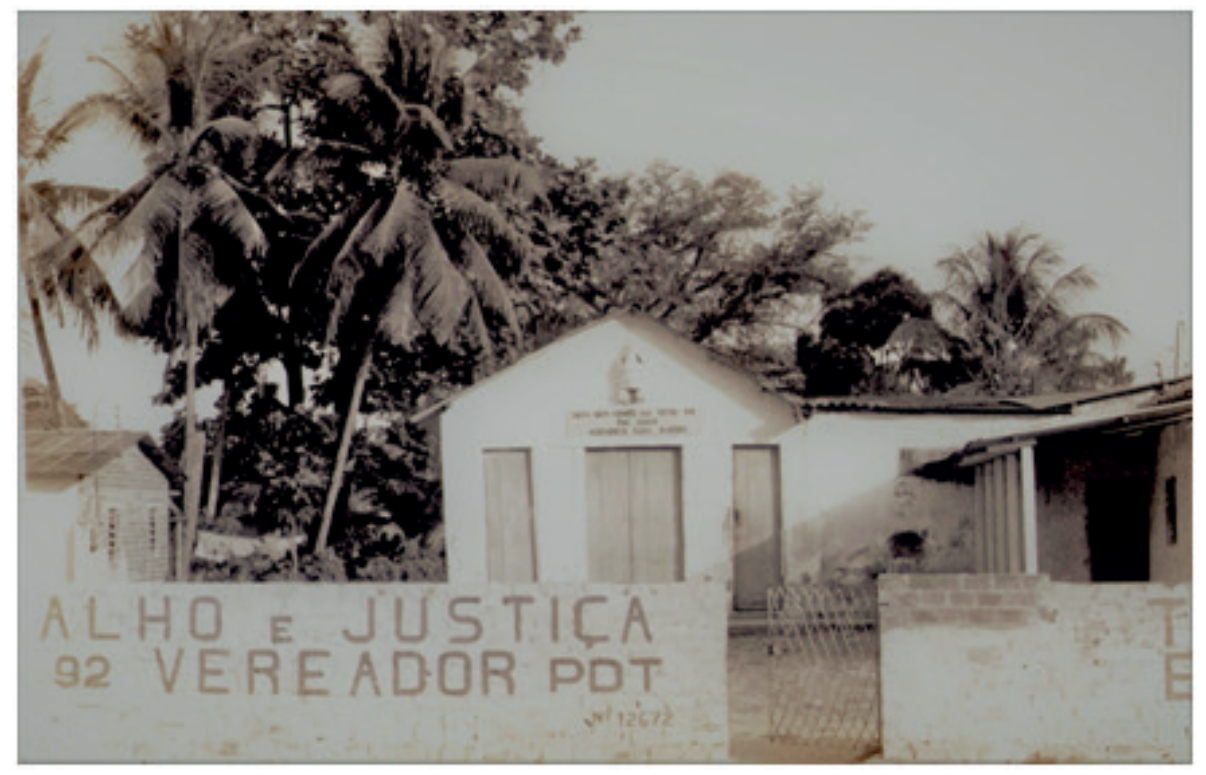

Figura 3 - Construção Principal em 1992

Foto: Ítalo Dantas

Já Manoel Nascimento Costa, atual Pai de Santo do terreiro, afirmou que ele, juridicamente, é tido como "Terreiro Senhora Sant'Ana, mas possui o nome tradicional Obá Omim, Rainha da Água” (COSTA,1992).

Fundado em 1872, localiza-se na Estrada Velha de Água Fria, número 1644, no bairro de Água Fria, periferia da cidade do Recife (LIMA, 2019). É um terreno enorme e que no passado teve um tamanho duas vezes maior. Lá se acumulam um conjunto de construções e espaços sagrados, destinados ao culto dos Orixás e dos ancestrais Eguns ${ }^{4}$, fundamentados ${ }^{5}$ na tradição Nagô ${ }^{6}$. Outro conjunto de construções profanas revelam que lá residem um aglomerado de pessoas, cujas unidades domésticas se distribuem desordenadamente por todo o terreno. O espaço físico é ocupado pelos descendentes do Pai Adão (Felipe Sabino da Costa), personagem que exerceu um papel fundamental na construção da imagem tradicional deste terreiro nas primeiras décadas do século XX (PEREIRA C., 1994). 
$\mathrm{Na}$ frente do terreiro se encontra a casa principal. Do seu lado esquerdo uma Casa, que até o ano de 2010, era ocupada por Maria do Bonfim $^{7}$ (Mãezinha), filha de Adão. Do lado direito, conjugada à construção principal, a casa do Sr. Walfrido (sobrinho de Adão). Na parte de trás do terreno, foram construídos em torno de sete pequenas casas (algumas de taipa), onde vale a pena ressaltar a da família de D. Luíza ${ }^{8}$ e de Tomé, sobrinho-neto de Adão9 ${ }^{9}$ e uma antiga oficina, que pertencia a um filho de Mãezinha ${ }^{10}$. Nos terrenos posteriores, há dois fatores importantes a salientar: uma cacimba dedicada à orixá Oxum e o fato de até recentemente ter existido um enorme pé de gameleira chamado Irokô ${ }^{11}$, árvore sagrada venerada como orixá.

$\mathrm{O}$ acesso à construção principal, destinada apenas às atividades sagradas, ocorre através de um salão ligado diretamente ao quarto do santo (peji), à cozinha do santo, a um banheiro, a um compartimento dedicado a instalações do Ponto de Cultura, a uma residência, e a um "hall" por onde se chega ao salão de toques. Ali estão expostas várias fotografias. Desde retratos antigos de Pai Adão, seus filhos José Romão, Malaquias, Mãezinha, a fotos mais recentes de festas, eventos e de integrantes mais novos do terreiro.

O salão de toques é o mais espaçoso ambiente da casa. É simples, tendo como enfeite uma Iemanjá pintada com os dizeres: "A Paz Esteja Aqui”. À esquerda existe uma porta através da qual se chega ao quarto do culto aos ancestrais Eguns (ritual privado masculino), composto de dois compartimentos. Nas paredes, várias fotos de Pai Adão, de Manoel Papai, Mãe Janda, sua mãe biológica, entre outras. Possui outro acesso externo, o que permite ao público participar dos festejos, sem, contudo, penetrar nos demais cômodos da casa. Conjugada à esquerda desta construção, encontra-se a capela de Santa Inês, nos moldes católicos, com entrada independente e sem ligação com o resto da casa.

A arquitetura, no que diz respeito às atividades sagradas, apresenta uma característica peculiar com relação a outros terreiros observados por nós na Região Metropolitana do Recife ${ }^{12}$. Trata-se do quarto de santo (peji), que não está ligado diretamente ao salão de toques, como é encontrado em outros terreiros. Esta singularidade explica-se pelo fato de ele ter sofrido várias reformas ao longo do tempo. $\mathrm{O}$ atual salão de toques só foi construído posteriormente ${ }^{13}$.

Foi tombado inicialmente, em plano estadual, através do decreto 10.712, de 05 de setembro de 1985, que homologa a Resolução do Conselho Estadual de Cultura ${ }^{14}$.

No ano de 2009, foi encaminhado à Superintendência Regional do IPHAN o pedido de tombamento na esfera federal ${ }^{15}$. O documento assinado pelo chefe religioso do terreiro, Manoel Nascimento Costa, é subscrito, ainda, por representantes da Coordenação Geral do Movimento Negro Unificado (PE), da Diretoria do Ilê Ayé (BA), do Comitê Estadual de Promoção da Igualdade Étnico-Racial e pela Deputada Estadual Te- 
reza Leitão, do PT-PE, presidente da Comissão de Educação e Cultura da Assembleia Legislativa. Além dessas personalidades, são também signatários do pedido a Associação Brasileira de Yalorixás e Babalorixás do Estado de Pernambuco (Abycabepe) e o Centro de Cultura Afro Pai Adão.

O conjunto diversificado de apoios mobilizado pelos dirigentes do Sítio já nos permite ter uma noção do alcance da reivindicação pelo tombamento, que extrapolou os limites da comunidade de culto, e mesmo do universo religioso afro-brasileiro, para incluir políticos e militantes de movimentos sociais. Uma demonstração clara do interesse de determinadas parcelas da população no tombamento do terreiro, visto não apenas como uma iniciativa de preservação da cultura afro, mas como uma conquista do povo pernambucano.

Também os argumentos apontados no documento como justificativa para o tombamento da Casa nos possibilitam perceber como os diversos temas que estamos analisando neste artigo são rearranjados dentro de um discurso específico. Logo no início, o documento enfatiza a vinculação da casa religiosa com as manifestações culturais. Como informa o texto:

O Sítio assumiu e assume o seu papel de reunir tradições culturais afrodescendentes, sendo palco e cenário de manifestações culturais profundamente integradas à vida do Recife, tais como: O Maracatu Elefante com sua legendária Rainha Dona Santa; com o Maracatu Leão Dourado com o Babalaô Luís de França, além de fortes relações com o Carnaval, o São João e outras manifestações populares e identitárias de um vasto patrimônio cultural que é vivido, mantido, preservado e, principalmente, transmitido às novas gerações (BRASIL, 2009. Grifos nossos).

Apesar da sua história centenária como casa de culto e da sua especificidade dentro do universo religioso afro-brasileiro, é através da sua contribuição à cultura que o Sítio inicialmente se apresenta. Essa cultura é também duplamente adjetivada como popular e afrodescendente, sendo, portanto, parte constitutiva da identidade dessa parcela da população. É, portanto, pela dupla entrada - da cultura e da identidade étnica - que a reivindicação de tombamento se fundamenta, levando em conta ainda: "a atual política do MINC/IPHAN, que valoriza as formas de expressão, os acervos que atestam a diversidade de povos e culturas que formam o Brasil e assim dão identidade ao brasileiro" (BRASIL, 2009).

O texto prossegue chamando a atenção para o fato de que Pernambuco não tinha, até então, nenhum terreiro tombado, embora tivesse no seu território casas de culto de igual valor àquelas existentes na Bahia e no Maranhão, estados que já possuíam terreiros tombados. E termina dizendo: "Acreditando nessa compreensão de patrimônio cultural, capaz de traduzir a forte e decisiva presença africana na formação social e cultural do Recife, de Pernambuco e do Brasil, nasce esta solicitação que reflete o desejo de uma comunidade que vive sua história e sua tradição" (BRASIL, 2009. Grifos nossos). 
Este trecho final parece fornecer os elementos que possibilitam a interpretação para todo o contexto que cerca o documento - seus apoios, seu conteúdo explícito e, finalmente, a sua aceitação. Trata-se, ao menos para alguns dos atores sociais envolvidos nessas demandas, de uma espécie de ação afirmativa histórica que busca, através do reconhecimento da contribuição cultural das matrizes africanas e indígenas, reescrever a história da formação da sociedade brasileira, corrigindo o viés eurocêntrico que a tem caracterizado. Sob esse ponto de vista, são as ligações das religiões afro-brasileiras com a herança africana (expressa também nas manifestações culturais) que fazem delas objetos privilegiados das políticas de reconhecimento e preservação. Como se pode depreender desse trecho do parecer positivo sobre o pedido de tombamento do Sítio:

O Sítio do Pai Adão é perante os demais Terreiros de Xangô do Recife e Pernambuco, bem como na região Nordeste, de reconhecido valor histórico e religioso [...]. Considerado um lugar notável enquanto verdadeira referência e memória ancestral de povos africanos hoje localizados na Nigéria. Auferindo, assim, ao terreiro reconhecimento na preservação das suas características por meio de um rico repertório de tradições orais, músicas, dança, indumentária, tecnologias artesanais, medicina, sistemas alimentares e demais manifestações que autenticam seu valor de terreiro fundador do Recife (LODY, 2009).

O Sítio do Pai Adão conta com forte apoio da sociedade pernambucana e com o reconhecimento de adeptos e estudiosos em função da sua tradição e fidelidade aos preceitos africanos.

No projeto elaborado pelo IPHAN para o tombamento do Sitio do Pai Adão, encontramos como parte da justificativa para essa intervenção os seguintes argumentos: "Considerado um modelo de culto sob todos os aspectos: o número de divindades cultuadas (consta que este terreiro cultua entidades não encontradas em outros terreiros do Brasil); sofisticação ritualística e qualidade das músicas e da execução de danças rituais" (BRASIL, 2010).

Em que pese a existência, no mesmo documento, de referências à história do terreiro e ao seu reconhecimento no conjunto da comunidade religiosa afro-brasileira, a avaliação reproduzida acima permite algumas reflexões: trata-se de um espetáculo artístico; a ser considerado em função da qualidade, sofisticação do modo como se apresenta? E se apresenta a quem? A um público de não adeptos? A um connaisseur que avalia a qualidade das músicas e da dança? E o que vem a ser um modelo de culto? Quem o estabelece?

Em 21 de setembro de 2018, o colegiado do Instituto do Patrimônio Histórico e Artístico Nacional (IPHAN), por unanimidade, concedeu o título de patrimônio cultural do Brasil ao Ilê Obá Ogunté.

O processo foi lido pela Conselheira Carla Casara. A partir das justificativas elencadas, vale ressaltar que o processo demandou nove anos para a confirmação e a reafirmação dos valores associados ao bem. Sob 
o aspecto jurídico, foi analisado e aprovado em duas ocasiões em 2016. Após a leitura do extenso relatório, a presidenta do Conselho Consultivo do Patrimônio Cultural solicita:

Os conselheiros que concordam com o tombamento do terreiro llê Obá Ogunté, Sítio do Pai Adio, situado na Estrada Velha de Água Fria, 1644, no bairro de Água Fria, no município de Recife, Estado de Pernambuco, e sua inscrição no Livro do Tombo Histórico e no Livro do Tombo Arqueológico, Etnográfico e Paisagístico, neste caso, com valores etnográficos e paisagístico, em função das árvores sagradas, por favor, levantem a mão. Está tombado, por unanimidade, o Terreiro do Sítio do Pai Adão, com inscrição no Livro do Tombo Histórico e no Livro do Tombo Arqueológico, Etnográfico e Paisagístico, nos termos do parecer da relatora (BRASIL, 2018).

A reunião do colegiado aconteceu no Forte de Copacabana, no Rio de Janeiro, devido a sua relevância histórica ${ }^{16}$.

\section{CONSIDERAÇÕES FINAIS}

Os processos de patrimonialização e musealização tomam grande relevo no século XXI e se constituem, ao que parece, em excelentes táticas de afirmação da identidade, uma vez que geram legitimidade no campo social e político.

Desde então, os terreiros e demais manifestações da identidade cultural afro-brasileira (sempre mais afro e menos brasileira) vivem em uma conjuntura fértil de possibilidades e incentivos para a "colocação das instituições de memória ao serviço do desenvolvimento social, bem como na compreensão teórica e no exercício prático da apropriação da memória e do seu uso como ferramenta de intervenção social" (CHAGAS, 2002, p. 55).

Diversas ferramentas teóricas e várias formas de chancelas, simbólicas e jurídicas, têm sido produzidas - pela academia e pelo Estado - e colocadas a serviço desta intervenção social, que lida não apenas com a religião, mas com a questão identitária como um todo.

O caso apresentado permite refletir sobre o modo como as reivindicações identitárias, trazidas à cena pelos movimentos sociais negros, e a ampliação no conceito de patrimônio conjugaram-se para situar as religiões afrodescendentes no centro de um debate político.

Estamos diante de um processo de reinvenção das religiões afro-brasileiras que está imbricado nas (re)construções identitárias do povo negro, suas buscas por afirmação, valorização de sua cultura e religiosidade.

Esses processos políticos, essas transformações no campo da cultura, da economia e da sociedade levaram as populações afrodescendentes a repensarem suas práticas, seus rituais, suas indumentárias, ou seja, a 
entrar em sintonia com os acontecimentos globais, inclusive no que se refere a questões de tombamento material e imaterial.

Retomando a relação das religiões afro-brasileiras e a construção de uma identidade negra, pode-se pensar como Woodward que a dispersão de pessoas pelo mundo "produz identidades que são moldadas e localizadas em diferentes lugares e por diferentes lugares. Essas novas identidades podem ser desestabilizadas, mas também desestabilizadoras" (2009, p. 22).

A partir daí, deve-se refletir sobre o reconhecimento dos terreiros como patrimônio, e as consequentes mudanças na sua relação com a sociedade, com as outras religiões, o Estado e os movimentos sociais. Essas relações produzirão novas identidades desestabilizadas ou desestabilizadoras? Este é um tema para futuras discussões.

\section{NOTAS}

1. Gomes (2012), ao analisar a atuação do Movimento Negro na educação, explica que a ideia de raça é entendida como construção social que marca, de forma estrutural e estruturante, a sociedade brasileira. Por sua vez, essa reflexão se assenta nos estudos pós-coloniais, que aventam a sua centralidade nos países com passado colonial e a sua operacionalidade nas relações de poder, as quais têm sido mantidas e subsistem no pensamento moderno ocidental.

2. Weffort foi Ministro da Cultura no governo de Fernando Henrique Cardoso de 1995 a 2002.

3. Livro de Registro dos Saberes; das Celebrações; das Formas de Expressão e dos Lugares.

4. Eguns são as almas dos mortos ancestrais.

5. O termo fundamento significa, em linguagem afro-brasileira, a justificação, a base, o alicerce simbólico de um rito, de uma crença ou de um terreiro (BRANDÃO; MOTTA, 2002, p. 75-76).

6. Nome dado no Brasil, ao grupo dos escravos sudaneses procedentes do país Iorubá (CACCIATORE, 1988, p. 178).

7. Falecida em 08 de março de 2010.

8. Falecida em 2018.

9. Falecido em abril de 1989.

10. Também falecido há cerca de três anos.

11. Em 09 de novembro de 2018, vândalos invadiram o terreno e incendiaram a árvore. Em 09 de janeiro de 2019, ela veio abaixo. O iroko era tombado pela Prefeitura da Cidade do Recife, por meio do Decreto Municipal no 14.288/1988, pela FUNDARPE e pelo IPHAN.

12. Nossas pesquisas nos terreiros indo-afro-brasileiros na Região Metropolitana do Recife tiveram início na década de 1980. Dos muitos visitados e pesquisados podemos citar a Roça Jeje Osún Opará Oxossy Ybualama, o Ilê Axé Oyá Meguê, o Palácio de Iemanjá, a Tenda de Umbanda e Caridade Caboclo Flecheiro, o Ilê Axé Ogunrinuwolá, o Ilê Obá Aganjú Okoloyá e muitos outros. Em nenhum deles encontramos estrutura arquitetônica similar à aqui descrita. 13. Entre os anos de 1994, quando terminamos nossa pesquisa de campo para 
dissertação de mestrado, e 2019, percebemos várias outras reformas. Como a cozinha, por exemplo, que foi reformada e mais bem equipada.

14. Pernambuco (1985).

15. Os documentos que compõem o processo de tombamento do Sítio do Pai Adão foram consultados na sede da Superintendência Regional do IPHAN em Pernambuco.

16. Brasil (2018).

\section{REFERÊNCIAS}

COSTA, Manoel Nascimento. O Terreiro Obá Ogunté: parentesco, sucessão e poder. [Nov. 1992]. Entrevistador: Zuleica Dantas Pereira Campos. Recife-PE, 1992. Fita k7.

BASTIDE, Roger. Imagens do Nordeste místico em branco e preto. Rio de Janeiro: O Cruzeiro, 1945.

BONFIM, Maria do. O Terreiro Obá Ogunté: parentesco, sucessão e poder. [Fev. 1992]. Entrevistador: Zuleica Dantas Pereira Campos. Recife-PE, 1992. Fita k7.

BRANDÃO, Maria do Carmo; MOTTA, Roberto. Adão e Badia: carisma e tradição no Xangô de Pernambuco. In: SILVA, Vagner Gonçalves da (Org.) Caminho das Almas: memória afro-brasileira. São Paulo: Summus, 2002.

BRASIL. Constituição da república federativa do Brasil, 1988. Disponível em: <http://www.planalto.gov.br/ccivil_03/constituicao/constitui\%C3\%A7ao.htm>. Acesso em: 07 jul. 2020.

BRASIL. Decreto n. 3.551, de 4 de agosto, 2000. Institui o Registro de Bens Culturais de Natureza Imaterial que constituem patrimônio cultural brasileiro, cria o Programa Nacional do Patrimônio Imaterial e dá outras providências. Disponível em: <http://www.planalto.gov.br/ccivil_03/decreto/d3551.htm>. Acesso em: 15 out. 2019.

BRASIL. Decreto-Lei $n^{\circ} 25$, de 30 de novembro de 1937. Disponível em: $<$ http://www.planalto.gov.br/ccivil_03/decreto-lei/del0025.htm>. Acesso em: 07 jul. 2020.

BRASIL. Instituto do Patrimônio Histórico e Artístico Nacional IPHAN. Ata da 90" Reunião do Conselho Consultivo do Patrimônio Cultural - Rio de Janeiro/RJ, de 20 de setembro de 2018. Disponível em: <http:// portal.iphan.gov.br/uploads/atas/ata_90_2009.pdf>. Acesso em: 07 jul. 2020

BRASIL. Instituto do Patrimônio Histórico e Artístico Nacional IPHAN. Pedido de Tombamento do Sítio do Pai Adão, 2009. Disponível em: $<$ http://portal.iphan.gov.br/uploads/atas/ata_90_2009.pdf>. Acesso em: 07 jul. 2020.

BRASIL. Instituto do Patrimônio Histórico e Artístico Nacional IPHAN. Resolução $n^{\circ}$ 01/2006, publicada em 23 de março de 2007. Disponível em: <http://portal.iphan.gov.br/uploads/ckfinder/arquivos/Re- 
solucao_001_de_3_de_agosto_de_2006.pdf >. Acesso em: 07 jul. 2020. BRASIL. Instituto do Patrimônio Histórico e Artístico Nacional IPHAN. Processo de Tombamento do Sítio de Pai Adão, v. 1, p. 13, 2010.

BRASIL. Presidência da República. Secretaria de Políticas da Promoção da Igualdade Racial. Relatório da $1^{a}$ Conferência Nacional da Promoção da Igualdade Racial, 2005. Disponível em: <http://www.seppir.gov.br/publicacoes/conapirI.pdf>. Acesso em: 18 out. 2019.

CACCIATORE, Olga G. Dicionário de cultos afro-brasileiros. 3. ed. Rio de Janeiro: Forense-Universitária, 1988.

CHAGAS, Mário. Memória e poder: dois movimentos. Cadernos de sociomuseologia: Museu e políticas de memória, Lisboa: Universidade Lusófona de Humanidades e tecnologias, n. 19, p. 35-68, 2002.

CHUVA, Marcia Regina Romeiro. Fundando a nação: a representação de um Brasil barroco, moderno e civilizado. Topoi, Rio de Janeiro, v. 4, n.7, p. 313-333, jul./dez. 2003. Disponível em: <http://www.revistatopoi.org/numeros_anteriores/Topoi\%2007/topoi7a4.pdf>. Acesso em: 01 out. 2019.

CORREAA, Alexandre Fernandes. "Novos Patrimônios e novos museus: vocação museológica dos tombamentos etnográficos". In: Revista Pós Ciências Sociais, São Luis, v. 4, n. 7, jan./jun. 2007. Disponível em: <http:// www.ppgcsoc.ufma.br/index.php?option=com_content\&view $=$ article\&id $=226 \&$ catid $=58 \&$ Itemid $=114>$. Acesso em: 04 set. 2019 .

CUNHA, Juliana da M. Quem pode mais do que o dono da casa? Participação social no processo de patrimonialização do Terreiro Ilê Obá Ogunté (Sítio de Pai Adão) no Recife-PE. 2018. 138 f. Dissertação (Mestrado Profissional Preservação do Patrimônio Cultural) - Instituto do Patrimônio Histórico e Artístico Nacional, Rio de Janeiro, 2018.

FERNANDES, Gonçalves. Xangôs do Nordeste: investigação sobre os cultos negros fetichistas do Recife. Rio de Janeiro: Civilização Brasileira, 1937.

FONSECA, Maria Cecília Londres. Referencias culturales: bases para nuevas politicas de patrimônio: In: BRASIL. Patrimônio Inmaterial: El Registro del Patrimonio Inmaterial: dossier final de las atividades de la comissíon y del Grupo de Trabajo Patrimonio Inmaterial. Brasília: Ministério da Cultura de Brasil/Instituto do Patrimônio Histórico e Artístico Nacional, 2002.

GOMES, Nilma L. Movimento Negro e educação: ressignificando e politizando a raça. Educação \& Sociedade, Campinas, v. 33, n. 120, p. 727-744, jul./set. 2012. Disponível em: <https://www.scielo.br/pdf/es/ v33n120/05.pdf>. Acesso em: 12 jul. 2020.

JUNDURIAN CORÁ et al. In: BRASIL. Programa Nacional do Patrimônio Imaterial: análise dos 10 anos de implantação. 2011. Disponível em: <http:// anaisenapegs2011.cariri.ufc.br/dmdocuments/p150.pdf $>$. Acesso em: 12 ago. 2019. 
LIMA, Claudia M. de A.R. IFATINUKË: entre-lugares, embarques e desembarques em costas brasileiras e africanas: um estudo sobre representação identitária na religião de matriz iorubá/nagô, em Pernambuco. 2019. Tese (Doutorado em Ciências da Religião) - Universidade Católica de Pernambuco, Recife, 2019.

LODY, Raul. Parecer. In: BRASIL. Instituto do Patrimônio Histórico e Artístico Nacional - IPHAN. Pedido de Tombamento do Sítio do Pai Adão, 2009. ORTIZ, Renato. Anotações sobre religião e globalização. Anàlisi, n. 29, p. 81-102, 2002. Disponível em: <http://www.scielo.br/pdf/rbcsoc/ v16n47/7720.pdf $>$. Acesso em: 18 out. 2019.

PERNAMBUCO. Decreto Estadual n. ${ }^{\circ}$ 10.712, de 05 de novembro de 1985. Homologação do tombamento do Sítio de Pai Adão.

PEREIRA C., Zuleica D. O Terreiro Obá Ogunté: parentesco, sucessão e poder. 1994. 157 f. Dissertação (Mestrado em Antropologia) - Universidade Federal de Pernambuco, Recife, 1994.

RECIFE.Decreton.14.288, de 16 de junho de 1988. Disponível em: < https:// leismunicipais.com.br/a1/pe/r/recife/leiordinaria/1988/1507/15072/ leiordinaria-n-15072-1988> . Acesso em: 18 out. 2019.

RECIFE. Lei n.15.072, de 08 de junho, 1988. Disponível em: <https:// leismunicipais.com.br/a1/pe/r/recife/lei-ordinaria/1988/1507/15072/ leordinaria-n-15072-1988>. Acesso em: 18 out. 2019.

SCHEINER, Tereza. Museologia ou patrimoniologia: reflexões. In: GRANATO, Marcus; SANTOS, C. P. dos.; LOUREIRO, M.L.N. (Orgs.) Museu e museologia: interfaces e perspectivas. Rio de janeiro: MAST, 2009. p. 43-60.

SERRA, Ordep. Monumentos negros: uma experiência. Revista Afro-Ásia, Salvador, n.33, p.169-205, 2005.

VELHO, Gilberto. Patrimônio, negociação e conflito. Mana [on-line], v. 12, n. 1, p. 237-248, 2006. Disponível em: <https://doi.org/10.1590/ S0104-93132006000100009>. Acesso em: 18 nov. 2019.

WEFFORT, Francisco. Carta de exposição de motivos ao Presidente. $O$ Registro do Patrimônio Imaterial: dossiê final das atividades da comissão e do grupo de trabalho Patrimônio Imaterial Brasília: Minc/IPHAN, 2003.

WOODWARD, Kathryn. Identidade e diferença: uma introdução teórica e conceitual. In: SILVA, Tomaz Tadeu da. (Org.). Identidade e diferença: a perspectiva dos estudos culturais. 9. ed. Petrópolis: Vozes, 2009. 